\section{Assessing the Urban Design Appropriateness of xiaoqu: the Case of Pujiang Town, Shanghai}

\section{Marco Capitanio}

Keio University, School of Science and Technology, 3-14-1 Hiyoshi, Kohoku-ku, Yokohama, Kanagawa 223-8522 Japan

*Corresponding author: capitanio@keio.jp

\section{Гrossef} http://dx.doi.org/10.5755/j01.sace.21.4.18926
A liveable neighborhood is the result of a multitude of factors, actors and circumstances, pertaining, among other things, to the built-environment, the socio-political and the economic context, adjusting over time. As in Shanghai numerous new towns are being built, urbanization growth has been researched mainly from a large-scale and quantitative point of view. A discourse on liveability is a necessary step to combine a more qualitative-based approach. This paper deals with the analysis and possible improvements of Shanghai's peripheral developments, especially focusing on the neighborhood scale in a middle-class context. A contextualization of the new towns' inception and main issues will provide the necessary background knowledge, and specific attention will be drawn to the Chinese urban typology of the enclosed compound (xiaoqu). One case study will be analyzed - a relocation area in Pujiang Town (south) - investigated through three urban design factors: diversity of uses, walkability, and green and public space. These will highlight the crucial role of a certain mixture of uses and the need of specific architectural typologies to house them; the contradiction between sense of enclosure and social interaction; the mutating nature of public space. Following new 2016 urban guidelines promulgated by the central government, compounds are required to gradually open up their walls and fences; nevertheless, the resistance of residences and historical urban models in China will constitute a challenge to the implementation of these guidelines.

Keywords: Chinese new neighborhoods, Pujiang Town, Shanghai's peripheral areas, xiaoqu.

A considerable amount of literature has been published over the past two decades about patterns and pathways of Chinese urbanization. Nevertheless, while environmental (Gu et al., 2010; Song and Ding, 2009; Chiu, 2008) and socio-economic (Tomba, 2014; Yeung, 2006; Friedmann, 2005) outcomes were extensively researched, the role of urban design in creating liveable environments has remained overlooked. Since 1990, when it became possible for private developers to lease land from the government, Shanghai has been witnessing a high-speed construction pace. This resulted in congestion in the city center and uncoordinated development at the fringes, threatening the amount of arable- and open-land at disposal, and of water resources. To tackle these problems, in 2001 the municipality decided to embrace a decentralization policy, through the foundation of new towns in its periphery. Thus, industrial and population growth during the 2000s took place mainly in outer areas (Chiu, 2008; Wu and Phelps, 2008). Shanghai's population is expected to increase from ca. 17,8 mil. in 2015 to over 20 mil. in 2025 (UN-Habitat, 2013: 155), even though with a decreasing growth-rate.

\section{Introduction}

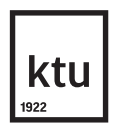

Journal of Sustainable Architecture and Civil Engineering Vol. 4 / No. 21 / 2017 pp. $29-40$

DOI 10.5755/j01.sace.21.4.18926 (c) Kaunas University of Technology 
New towns, thanks to a strong top-down, state-driven planning, and no organized resistance (Tomba, 2014), could be planned and built at a breakneck speed. They followed a global trend aiming at creating autonomous, high-class satellite developments catering elites in search of more greenery and less congested and polluted environs (Chen et al., 2009). Between 2000 and 2020 the government planned, in fact, "to relocate more than 1.15 million people to the suburbs" (den Hartog, 2010:36).

The distance to underground stations is often too big. One aim was to discourage commuting to the central districts, even though job opportunities in the new towns are scarce. In many cases, apartments were quickly sold out, but buyers turned out to be speculators. Moreover, since developments were carried out by private parties acquiring land use rights, a balanced mixture of services and public functions could often not be achieved, resulting in a critical lack of amenities and services. All this has been exacerbating Shanghai's increasing spatial segregation.

Contemporary urbanization patterns in Shanghai are spatialized through the xiaoqu (小区), literally 'small district'. Apart from residences, it can sometimes comprehend facilities like kindergartens, fitness centers, used also by people living outside the xiaoqu. This sort of development, given the stress on security and control issues, is referred to as 'compound'. It is usually constituted by a group of high-rise, south-oriented residential buildings, accessible through a limited number of patrolled gates and entrances. Compounds clearly separate the open space of the street outside from the semi-private space inside, thanks to fences or walls, usually combined with greenery. At the perimeter there can be found rows of outward-looking shops, and, in principle, every resident can open a business inside a compound, converting his or her apartment into a shop or office. The contemporary Chinese city can thus be understood as a 'compound archipelago' (Capitanio, 2012), holding drawbacks and potentials. Such urban pattern represents lack of urbanity and socio-spatial segregation, similar to gated communities, but, "[a]lthough the 'archipelago' of xiaoqu does not truly promote urban cohesion, the xiaoqus themselves do constitute a means for creating community identity." (den Hartog, 2010:380) Table 1 summarizes how the xiaoqu model bears morphological traits and social values fundamentally different from those of the historical European city.

Table 1

Spatial value system and morphology of the historical European city and of xiaoqu

\begin{tabular}{|c|c|c|c|}
\hline & Spatial value system & Morphology & "Place" is \\
\hline $\begin{array}{c}\text { Historical } \\
\text { European } \\
\text { urban model }\end{array}$ & $\begin{array}{l}\text { ramily/clan } \\
\text { society } \\
\text { public space }\end{array}$ & & $\begin{array}{c}\text { public } \\
\text { (e.g. street, } \\
\text { square) }\end{array}$ \\
\hline $\begin{array}{c}\text { Contemporary } \\
\text { Chinese urban } \\
\text { model } \\
\text { (xiaoqu) }\end{array}$ & & 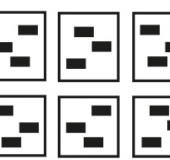 & $\begin{array}{c}\text { enclosed } \\
\text { (e.g. courtyard) }\end{array}$ \\
\hline
\end{tabular}

The aim of the research is to assess how certain urban design factors influence the spatial and social quality of a new neighborhood in the periphery of Shanghai, seen as a representative case of countless generic developments around the country. In this respect, it is necessary here to briefly define liveability and its relevance to urban design.

Even though it has often been equated to sustainability, there is a growing amount of literature that grants liveability a more autonomous role. Nonetheless, the two agendas tend to overlap. Some point out that liveability is more concerned with the present state of a city or neighborhood 
and is not so much focused on future outcomes. Others highlight the fact that measures of liveability are locational, i.e. stress the idea of place, while sustainability takes into account a broader range of variables (Ling and Yuan, 2009:156-7). In comparison with sustainability, liveability focuses more on specific human needs and people's reactions to places (see Wheeler, 2004). Its area of intervention is restricted to the neighborhood and city scale, focusing less on environmental metrics and more on human activities.

Some authors suggest that liveability results from the combination of urban environmental quality and human wellbeing (Kallidaikurichi and Yuan, 2010:192), so that "key elements of a liveable city often include attractive public spaces, walkable, mixed use, higher density neighbourhoods that support a range of green infrastructure and transport, affordable housing, [...] human-scaled pedestrian experiences." (Ling \& Yuan, 2009:3) Others prefer to focus on more quantifiable aspects, pairing liveability with low-carbon developments and lifestyles (Pickerill, 2013), while Wagner and Caves (2012) highlight the importance of community and social infrastructure. Sustainability and liveability go often hand in hand and they mutually support each other though. A liveable neighborhood is, thus, the result of a multitude of local actors and circumstances, pertaining, among other things, to the built and natural environment, the socio-political and economic context, adjusting over time. From this point of view, the significance of global liveability rankings is highly dubious, as Capitanio (2018) has pointed out in regard to the Japanese context.

Taking into account the most relevant liveability issues outlined in the introductory section, we focused our analysis on the following three fundamental urban design factors. The selection is based on a large body of literature addressing empirical methods to investigate urban environments (e.g. Dovey, 2016; Ye and van Nes, 2013; Jabareen, 2006; Frey, 1999; Jacobs, 1961).

Diversity of uses, tackling the mismatch between demand and offer of services in newly and quickly built neighborhoods (see Jenks and Dempsey, 2005:155). We will analyze the case study in two ways. On the one hand, quantitatively, calculating the amount of floor space devoted to different functions. These will be represented in a chart by a percentage over the total floor space of the area, thus indicating the degree of mix. It has to be noted that, even though we are analyzing diversity of uses, we take here into consideration just built space. Greenery and water space, land uses in their own right, will be separately tackled in a following factor. On the other hand, qualitatively, mappings will distinguish between kinds of business and typologies they are housed in, and will represent their spatial distribution over the case study area.

Walkability, assessing the degree of physical and psychological enclosure of xiaoqu. Walkability could be considered a sort of glue holding the city together, as it determines, among other things, accessibility to shops, quality of outdoor experiences, street character and usage. The degree of openness of a settlement, the quality and character of connections at ground floor and the presence of gates or fences determine, in fact, pedestrian behavior. In principle, interconnected streets and pathways are preferable over cul-de-sac and dead-end streets, which do not encourage transit. Nonetheless, the important meaning and long tradition of Asian alleyways (e.g. Japanese roji, Shanghainese lilong) or enclosed spaces (e.g. Beijing's hutong) should not be forgotten (see Radović, 2016). According to Madanipour (2016), accessibility is regulated by essentially three kinds of barriers. First, physical barriers, e.g. fences and walls. Second, perceived barriers like codes and signs, as 'we may be hesitant to enter an expensive-looking shopping center if we do not have access to the resources needed for the activities there'. Third, social control, e.g. legal prohibitions.

Green and public space, investigating the type of space at disposal and the presence of outdoor activities hinting at the social role played by such spaces (see Hassenpflug, 2010:147). In fact, the benefits of high-quality green space in cities is confirmed by both academic research and common knowledge. Municipalities, governments, citizens and civil society are constantly struggling to increase the amount of natural areas within their borders, but their performance and degree of 
Case study: Pujiang Town

\section{Fig. 1}

Location of the case study area within the whole Pujiang Town appropriation by local residents is often overlooked. In regard to our analysis, we will first map and quantify publicly accessible parks, green and water spaces, and paved "public" spaces. A qualitative analysis will follow, assessing the use, significance and performance of such spaces, based on on-site surveys, employing photographic material.

The analysis was carried out by means of fieldwork and on-site observations in the course of one year, while maps were compiled making use of satellite imagery.

Pujiang Town (蒲江) belongs to the decentralization plan called One City Nine Towns (Xue and Zhou, 2007). In 2001 the Italian firm Gregotti Associati won an invited competition to build an 'Italian-town' in Shanghai's southern district of Minhang. The office was responsible for the masterplan and an architectural implementation in the northern part of the district, targeting high-class buyers. The rest of the town has been designed by local companies and built by a number of different developers (Fig. 1). When Shanghai won the bid to host the 2010 World Expo, the municipality chose to redevelop an area on the eastern bank of the Huangpu river, resettling industries and

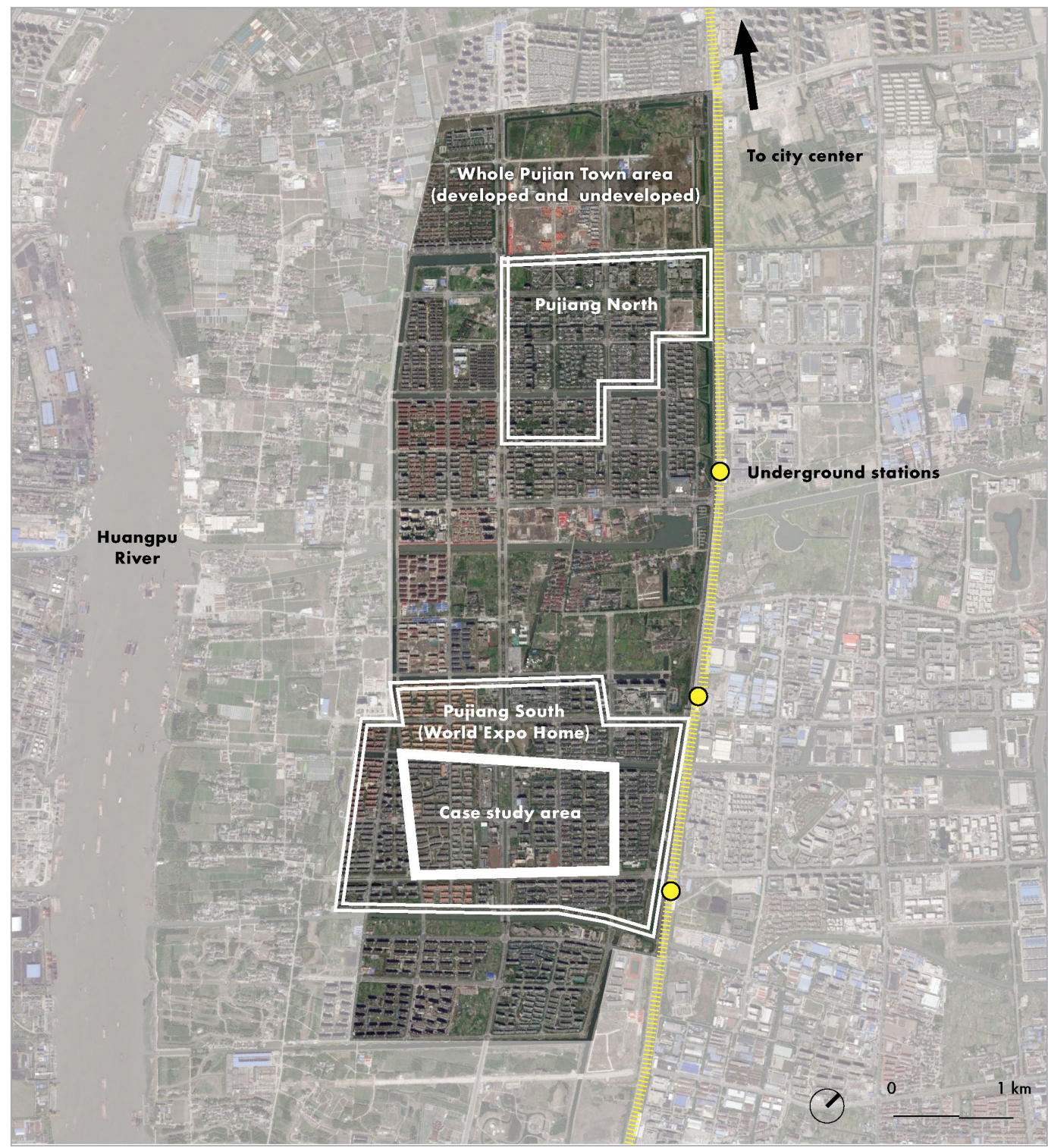


households located on that site. The southern part of Pujiang was selected as the area where to relocate these people. Moreover, farmers and peasants who used to live on Pujiang's site were relocated to the (southern) new town as well. Construction started in 2004 and was completed by 2006. 15'000 were the relocated households, spread over 15 blocks. Northern Pujiang is thus considerably different from the southern part: while the former aims at attracting higher-middle class, the latter (chosen as case study area) retains a generic character. The two parts share, nonetheless, the same street layout, composed of square blocks measuring $300 \mathrm{~m}$ on each side. Pujiang lies $15 \mathrm{~km}$ south of People's Square and it can be reached by subway (completed in 2009) in 45 minutes, even though the three stations' location, along the town's eastern edge, is not ideal. Nowadays, we face a heterogeneous mix of inhabitants: on the one hand there are relocated people, on the other hand middle-class households either renting an apartment or have bought one. A number of white-collar workers decided to move here, mainly because of convenient apartment prices. Meanwhile, farmers, who used to live in the same area, had to abruptly adapt to live in a new urban environment. Even though access to commercial facilities and other services for them has improved, they lack enough indoor storage space and cannot grow vegetables and raise livestock in front-yards as they used to.

The whole neighborhood presents a mid-rise character, with a degree of compactness comparable to compounds in Shanghai's central districts but with sensibly lower densities (Floor Area Ratio 1,4; Ground Space Index 0,25). Buildings are mostly 6- or 11-stories-high, the former usually located along the xiaoqu's borders, the latter towards the center of the compounds, more protected from street noise and pollution, thus more expensive.

Fig. 2 shows activities' distribution and morphological characteristics of the town. More than $80 \%$ of floor space in the area is devoted to residence. Being a relocation, virtually the totality of the apartments is inhabited. Public functions are represented by two schools and a kindergarten, serving the whole new town. Supra-neighborhood functions are clustered around the neighborhood's main central axis, namely the afore-mentioned schools, a Walmart supermarket (opened in 2011) and office buildings. Such uses are spatially detached from residential xiaoqu, becoming a block on their own. More than $80 \%$ of office space is empty.

It is possible to distinguish between two typologies of commercial activities: one belonging to the neighborhood scale and one to the district scale. The former is constituted by small businesses serving the daily needs of each xiaoqu, requiring a basic, almost standard architectural typology: a one-storey, narrow (2,5-5 m) shop. When more spacious (i.e. more expensive) typologies are built, they remain either empty, or their second floor is used, at best, for storage. Moreover, the lack of enough services is reflected by the conversion of ground floor apartments into informal businesses. Occasional informal stalls appear both inside and outside a xiaoqu.

The presence of workstations (various kinds of hardware reparations) indicates that light-industrial activities can coexist close to residences. Shops tend to form a bracket encircling a xiaoqu, either following the north-south axis - where no apartments would be placed for orientation reasons - or along major streets. Beside neighborhood-scale activities there are district-scale ones, such as Walmart. It hosts a number of restaurants, high-end stores, entertainment opportunities (with a high vacancy-rate though), targeting not only customers from immediate neighborhoods, but from the whole Pujiang Town. Though naturally a commerce-oriented spot, access is open to anyone, and, especially during weekends, it becomes an entertainment choice for families with children. While being popular among younger generations, elderly's behavior is noteworthy: they tend to gravitate and visit the shops along the perimeter of Walmart, but do not seem attracted by the inner courtyard. 
Fig. 2

Activities' distribution and town's morphology.

The color bar refers to the total floor space.

Photographs from

left to right: informal stall; brackets of shops along xiaoqu's border; apartment converted into shop

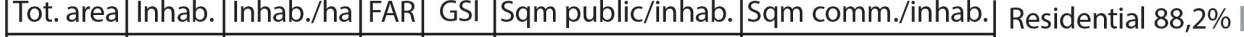

\begin{tabular}{|c|c|c|c|c|c|c|}
\hline 75ha & $12^{\prime} 000$ & 160 & 1,4 & 0,25 & 4,5 & 4,5 \\
\hline
\end{tabular}

Public 5,5\% Office $0,8 \%$
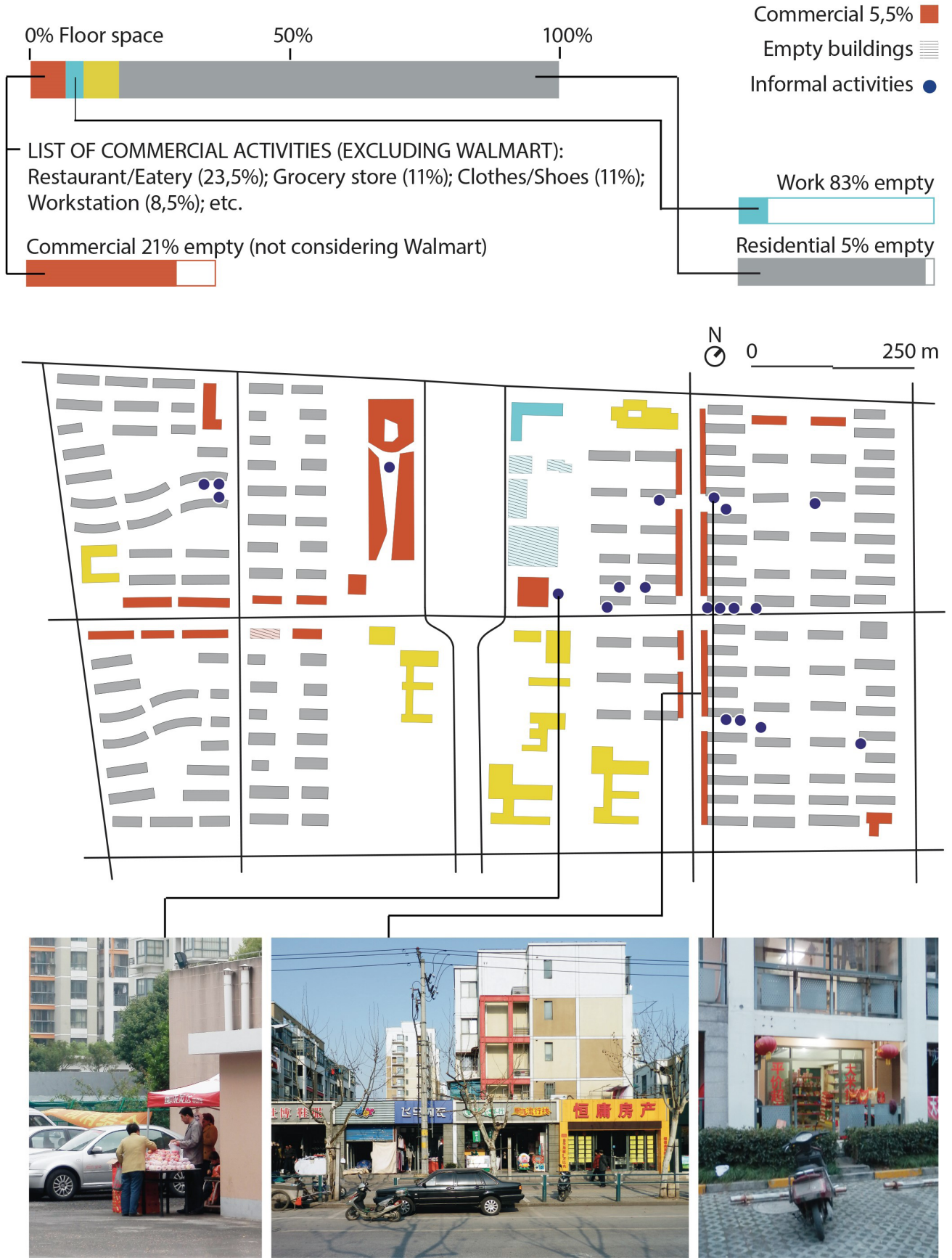

Fig. 3 shows the level of hermeticism of the case study. All xiaoqu present a typical pattern, with fences (occasionally substituted by shopping strips) and gates to regulate access. A majority of gates is patrolled by one/two guards, checking cars driving through, but rather indifferent to pedestrians. By means of on-site observation, everyone, including Caucasians, could enter with ease, so that locals can walk through a xiaoqu to shorten walking distances. In the entire case 
study area there are only two buildings completely free of fences, the Walmart and an office building on the opposite side of the street, beside a public square. The average distance between xiaoqu entrances is around 360 meters.

\begin{tabular}{|c|c|} 
Avg. No. entrances/xiaoqu & Avg. distance between entrances \\
\hline 2,6 & $360 \mathrm{~m}$ \\
\hline
\end{tabular}

Fence/wall IIIIIII
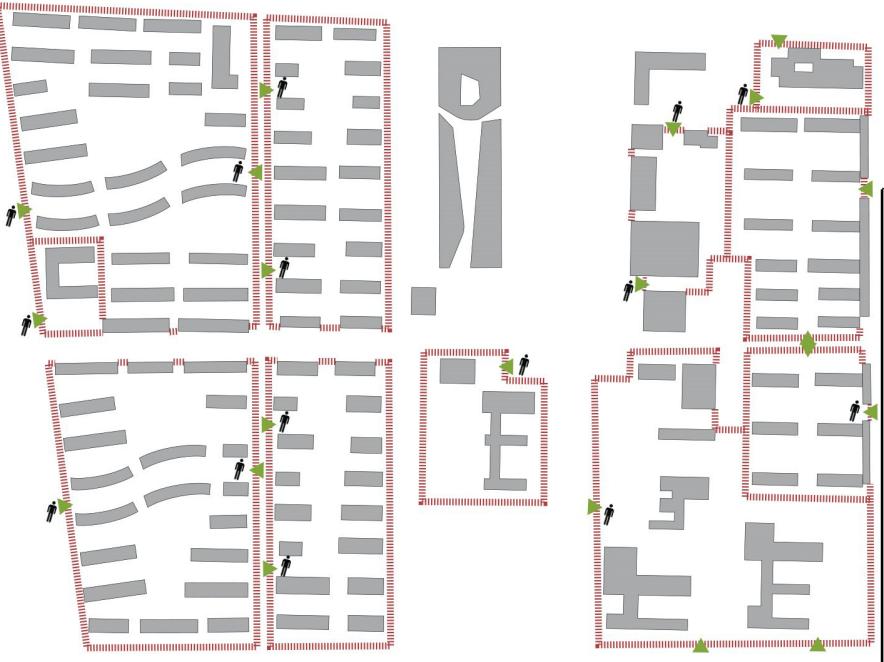

$\stackrel{N}{\bigcirc} \mathrm{O}$

0

$250 \mathrm{~m}$
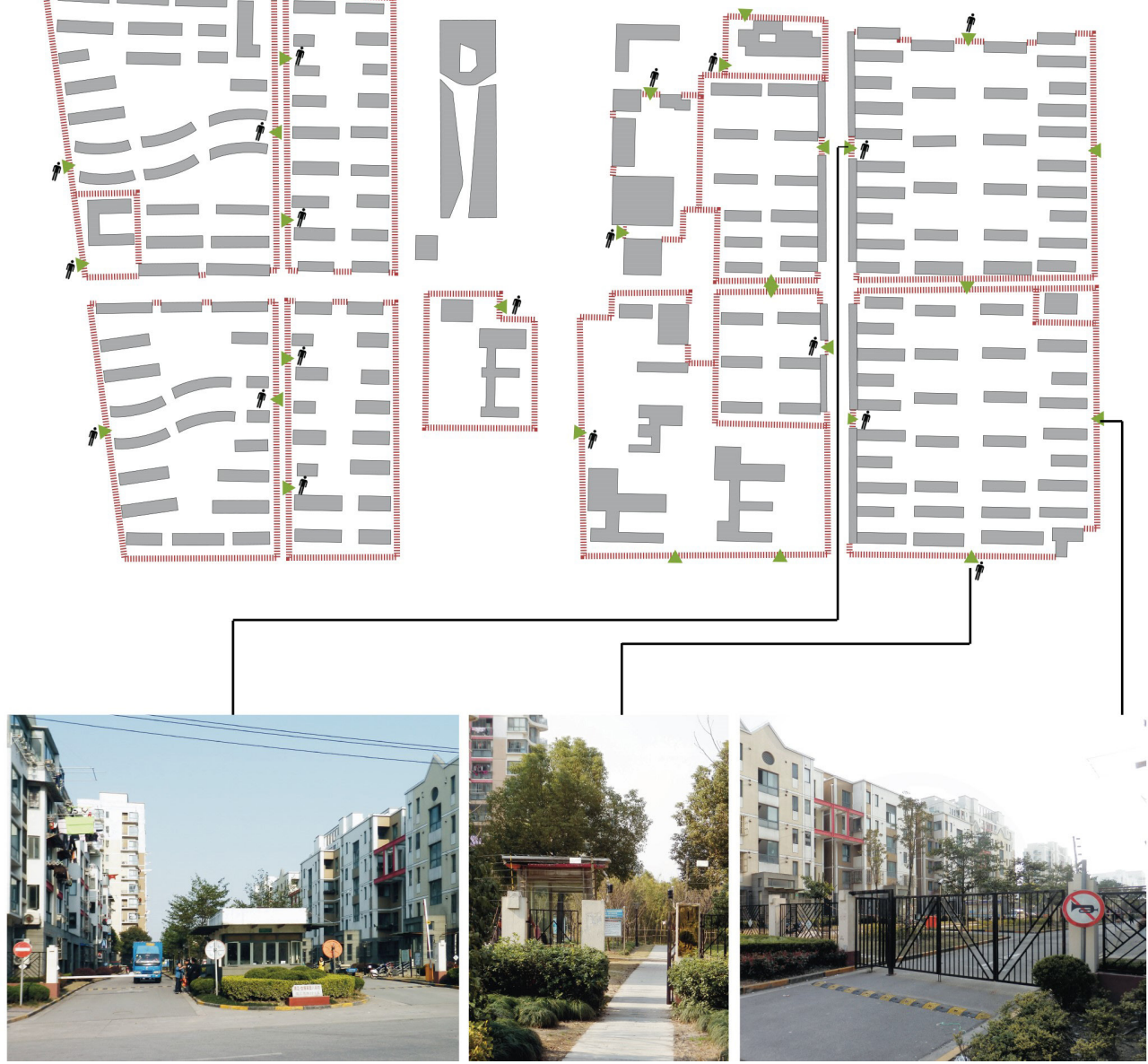

Fig. 4 shows the type and use of open areas. Space enclosed by fences or walls has always been considered as 'place', carrying meanings and shared values, since ancient China. From this point of view, it is no wonder that most outdoor recreational activities are happening inside the xiaoqu, often in landscaped areas with lawns, plants and trees. There can be found elderly chatting, playing or doing physical exercises, their bikes showing that some of them come from another xiaoqu. Open parks have still to be appropriated by local inhabitants though. They are used as transitional spaces, e.g. shortcuts, but not seen as places to be enjoyed, and, according to on-site observations, they were almost always deserted, even though their overall quality was better than green spaces inside xiaoqu.
Fig. 3

Hermeticism of xiaoqu. Photographs from left to right: patrolled car entrance unpatrolled pedestrian entrance; unpatrolled car entrance

\section{Green and public space}


A large plot of land, beside Walmart and located exactly along the central axis of Pujiang, because of its neglected and non-designed state was converted into an orchard, cultivated by different people. It is a hint that an amount of informal temporary uses is highly needed in case of quickly built and inhabited neighborhoods. Similarly to enclosed open spaces, commercial streets are an ordinary component of the historical Chinese city. The analyzed streets with shop brackets selling their goods and services were lively, while streets bordered by fences, especially the ones located far from the underground station or from public functions, hosted few passers-by. In regard to typologies imported from the West, in Pujiang south we found an example of an 'urban' square. A few people were sitting on their own, some of them eating, this situation giving a hint about a po-

Fig. 4

Type and use of open space. Photographs from left to right: underused park; Walmart's internal square; open space inside xiaoqu

\begin{tabular}{|c|c|c|} 
Sqm paved space/inhab. & Sqm park/inhab. & Sqm appropriated space/inhab. \\
\hline 1 & 1,7 & 2,5 \\
\hline
\end{tabular}
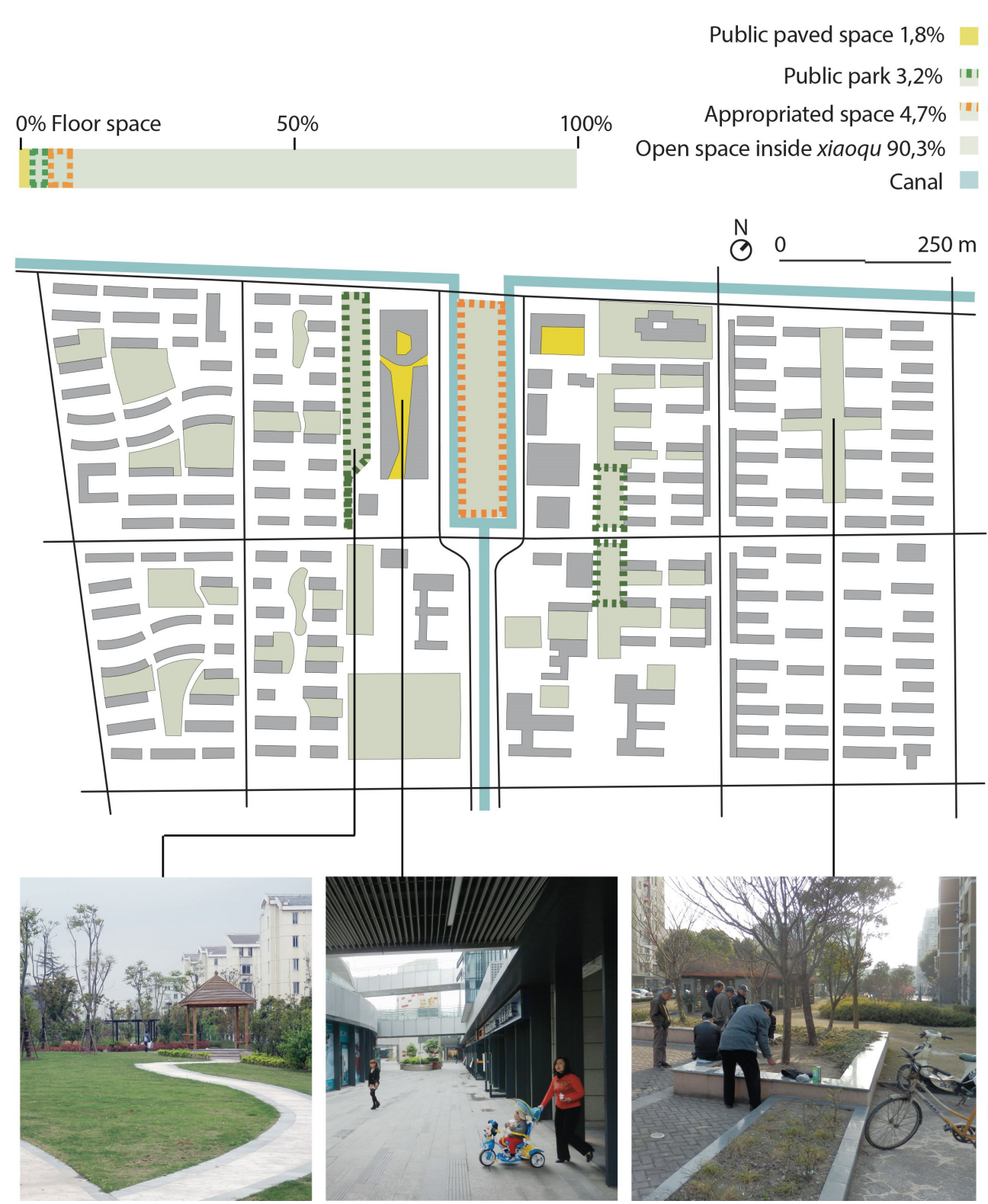
tential that could be more consciously exploited, if adequate services and businesses were located there. From this point of view, Walmart plays a great role as an attractor. Because of its numerous offers of services (including a post-office) it represents a central reference for the neighborhood's inhabitants. Its internal open spaces mimic an urban environment, halfway between an enlarged alley and a small plaza.

Diversity of uses is probably the single most important factor contributing to the liveability of new Chinese peripheries. A balanced mixture of uses, like in certain city-centers, is a historical process adjusting over time, and the problem that urban designers (among other professionals) have to face is: how to make instant neighborhoods work from the beginning? Obviously, the location of a new development adjacent to an existing town has the advantage of relying on already functioning infrastructure and services, while developing its own. In this respect, enormous progress could be made in terms of policy-making and planning in carefully selecting the most suitable sites where to build new communities.

Moreover, how do we set targets to define successful urban design? We maintain that each community has its own specific goals to achieve and issues to solve, and that the goal of urban design is to be appropriate to the context, i.e. being relative instead of normative or prescriptive. If in general terms neighborhoods should be diverse, human-scaled and relying on existing resources (Talen 2010:130), specific design strategies should be a response to concrete local calls. In this respect, from our case study analysis, the lack of enough servicees became evident. Office-space is often too expensive and grouped in clusters, remaining empty and creating vast unused lots in the town fabric. From this point of view, SOHOs should be fostered, spread in a more discreet way in every compound, helping creating a stronger mixture of people during different times of the day.

Commercial activities, according to our analysis, are in deficit, as proved by the example of inhabitants converting their ground-floor apartment into a business. Every compound should have, within walking distance, commercial activities targeting daily needs (e.g. restaurant/eateries, food-shops, grocery stores). Single-storey, narrow typologies suffice for this goal in most of the cases, while two-storey, larger and more expensive shops are often left empty. Brackets of shops, when present, are always designed along xiaoqu's borders; it seems worth to experiment with commercial typologies inside compounds, injecting functions targeting the entire neighborhood, such as a sport facilities, health-care services, entertainment. This could help breaking the isolation and hermeticism of the compound-archipelago by the mere fact that people living elsewhere would have a reason to enter another compound. Conversely, such a particular function could also be used as an element fostering identity, distinguishing through specialization one xiaoqu from the other. These opening-up steps could be achieved, though, only through a compromise with security issues, which, as noted throughout our analysis, are more symbolic than actually needed. Room for self-adjustments over time and the need of flexibility is visible in various kinds of informality, from the afore-mentioned shops opened at ground-floors of apartments, to agricultural activities on left-over plots of land, to various kinds of street stalls.

When planning and building are carried out quickly, without participation from the bottom, often the outcome is not calibrated to real needs. In this respect, temporary uses, especially related to agricultural purposes, should be recognized as having manifold beneficial effects. Inhabitants of Pujiang Town are just beginning to appropriate their neighborhood. By initiating informal activities and transforming the town's built space, they are gradually creating a bottom-up project fitting their needs.

Even though "the enclave should be understood as the typological success formula of market-controlled urbanization" (Mars and Hornsby, 2008:187), incidentally reflecting the traditional 
Chinese preference of familiar and community relationships over civic ones, this urban model is helping exacerbating social segregation, a harm for future societal well-being. Within this archipelago some islands stand out. They are neighborhood shopping centers, combining convenience, luxury goods and entertainment. They represent the emergence of a middle-class lifestyle, where entire families enjoy going out and spending weekends shopping (it is not a coincidence that many attractions inside such commercial centers are directed to children). They indicate the emergence of a hybrid kind of public space, one mainly devoted to commerce but capable of hosting a number of additional activities, thanks to its large squares, pedestrian alleys and mix of low- and high-quality services with corresponding prices. Our analysis confirms that "commercialization is [...] indispensable for the genealogy of [...] public spaces" (Hassenpflug, 2010:32) and that the private sector is destined to play an ever-increasing role in this process. When children, now used to go to a shopping center on a weekend, will grow up, those spaces will appear to them a natural and indispensable component of city-making.

Most of the urban design issues found in the case study relate to the lack of shopping options and services, mismatch between available and desired architectural typologies, lack of low-cost working spaces and allotments to cultivate, oversupply of offices, limited pedestrian permeability increasing walking distances. A possible strategic pathway to be followed, when aiming at progressively move away from the compound-archipelago model, could be to downscale the tendency toward specialization from the neighborhood- to the xiaoqu-level, so that a mix of uses happens within blocks rather than within districts.

Considering the past 100 years, Shanghai has been based on different kinds of walled or enclosed urban typologies, and failing to acknowledge this and to understand the forces behind the production of the Chinese city is a naïve standpoint. But to consider the xiaoqu a given model to be followed seems to us reactionary thinking; it should rather be challenged, since they are useful only as long as they provide an anchoring point for newly-established neighborhoods, as in the case of new towns. The xiaoqu could then be gradually transformed into a more inclusive model (abandoning gates, mixing uses on a finer grain, favoring low-rise but high-density typologies, etc.) once a community gains self-confidence. In fact, China's central government has recognized the drawbacks of the compound archipelago in its new 2016 guidelines for urban planning and construction management, calling for a gradual opening of compounds by building more access roads (新华社, 2016). These new regulations have unleashed a wave of discontent among apartment owners, who do not want to trade their privacy and sense of security for the public good. This case highlights the struggle between top-down and bottom-up initiatives, between individual interests and collective good. It remains to be seen with which methods and to which degree the central government will enforce the new regulations, and what kind of compromise between sense of enclosure, diversity of uses and higher walkability can be reached to increase liveability. In fact, "[a]s urbanization levels off dramatically in East Asia between 2030 and 2090 [...], will peri-urban areas become stranded remnant landscapes [...], or will they have consolidated into sustainable, [...] clustered [...] landscapes?" (Webster, 2011:642)

I would like to express my gratitude to Prof. Darko Radović, Prof. Davisi Boontharm, and Prof. Zhuang Yu for their helpful suggestions. My thanks go to Dr. Simone Garlandini for his constructive comments.

Funding for this research has been provided by GESL Program at Keio University, Tokyo, and by the German Academic Exchange Service (DAAD). 
Capitanio, M. Adjustments in the Compound Archipelago - Improving Liveability in Shanghai's Peripheral Neighborhoods. TU Berlin - Tongji University Shanghai; 2012. https://www.researchgate.net/ publication/282567354_Adjustments_in_the_Compound-Archipelago_Improving_Liveability_in_ Shanghai\%27s_Peripheral_Neighborhoods, accessed 31 January 2018.

Capitanio, M. The Relativity of Liveability Rankings: Examining the Japanese Case against the Global Discourse. World Journal of Social Science, 2018; 5(1): 12-18.

Chen, X., Wang, L., Kundu, R. Localizing the production of global cities: a comparison of new town developments around Shanghai and Kolkata. City \& Community, 2009; 8(4): 433-65.

Chiu, R.L.H. Shanghai's Rapid Urbanization: How Sustainable? Built Environment, 2008; 34(4): 532-46.

Dovey, K. Urban Design Thinking: A Conceptual Toolkit. London - New York: Bloomsbury Academic; 2016.

Frey, H. Designing the City: Towards a More Sustainable Urban Form. London: Routledge; 1999.

Friedmann, J. China's Urban Transition. Minneapolis - London: University of Minnesota Press; 2005

Gu C., Zhang X., Wang X. Climate Change and Urbanization in the Yangtze River Delta. Cambridge: Lincoln Institute of Land Policy. https://www.lincolninst.edu/pubs/download-thankyou.asp?doc_ id=1047, accessed 22 October 2016.

den Hartog, H. Shanghai new towns: searching for community and identity in a sprawling metropolis. Rotterdam: 010 Publishers; 2010.

Hassenpflug, D. The urban code of China. Basel: Birkhäuser Architecture; 2010.

Jabareen, Y. R. Sustainable Urban Forms : Their Typologies, Models, and Concepts. Journal of Planning Education and Research, 2006; 26(1): 38-52.

Jacobs, J. The Death and Life of Great American Cities. New York: Random House; 1961.

Jenks, M., Dempsey, N. Future Forms and Design for Sustainable Cities. Oxford: Elsevier Architectural Press; 2005.

Kallidaikurichi, S., Yuen, B. Developing Living Cities: From Analysis to Action. Singapore: World Scientific Publishing Company; 2010.

Ling, O.G., Yuan, B. World Cities: Achieving Liveability and Vibrancy. Singapore: World Scientific Publishing Company; 2009.
Madanipour, A. Social Exclusion and Space. In LeGates, R. and Stout, F. (Eds.) The City Reader. Pp. 203211. New York: Routledge; 2016.

Mars, N., Hornsby, A. The Chinese dream: a society under construction. Rotterdam: 010; 2008.

Pickerill, J. Building liveable cities. Urban Low Impact Developments as low carbon solutions? In Bulkeley, H. et al. (Eds.) Cities and Low Carbon Transitions. Pp. 178-197. London: Routledge; 2013.

Radović, D. Measuring the non-measurable: On mapping subjectivities in urban research. City, Culture and Society, 2016; 7(1): 17-24.

Shanghai Municipality. Shanghai Statistical Yearbook 2011. Shanghai: Shanghai Statistics Press. Shanghai Statistical Yearbook, http://www.statssh.gov.cn/data/toTjnj.xhtml?y=2011e, accessed 21 October 2016.

Song, Y., Ding, C. Smart Urban Growth in China. Cambridge: Lincoln Institute of Land Policy. 2009

Talen, E. The Geospatial Dimension in Urban Design. Journal of Urban Design, 2010; 16(1): 127-49.

Tomba, L. The government next door: neighborhood politics in urban China. New York: Cornell University Press; 2014.

UN-Habitat. State of the World's Cities 2012/2013 Cities for All: Prosperity of Cities. New York: Routledge; 2013

Wagner, F., Caves, R. Community Livability: Issues and Approaches to Sustaining the Well-Being of People and Communities. New York: Routledge; 2012.

Webster, D. An Overdue Agenda: Systematizing East Asian Peri-Urban Research. Pacific Affairs, 2011; 84(4): 631-642.

Wheeler, S. M. Planning for Sustainability: Creating Livable, Equitable and Ecological Communities. London: Routledge; 2004.

Wu, F., Phelps, N. From suburbia to post-suburbia in China? Aspects of the transformation of the Beijing and Shanghai global city regions. Built Environment, 2008; 34(4): 464-481.

Xue, C., Zhou, M. Importation and adaptation: building 'one city and nine towns' in Shanghai: a case study of Vittorio Gregotti's plan of Pujiang Town. URBAN DESIGN International, 2007; 12(1): 21-40.

Ye, Y., van Nes, A. The spatial flaws of new towns: Morphological comparison between a Chinese new and old town through the application of space syntax, spacematrix and mixed use index. Ninth International Space Syntax Symposium: Seoul; 2013. 
Yeung, Y. China's Urbanizing Population and Regional Integration. In Beijing: Shanghai-Hong Kong Development Institute, Honk Kong Institute of Asia-Pacific Studies; 2006.

新华社.中共中央 国务院关于进一步加强城市规 划建设管理工作的若干意见-新华网 [Opinions of the CPC Central Committee and the State Council on Further Strengthening the Management of Urban Planning and Construction - Xinhua News Agency]. 21 February 2016, http://news.xinhuanet.com/politics/2016-02/21/c_1118109546.htm, accessed 22 October 2016.

\section{About the author \\ MARCO CAPITANIO \\ $\mathrm{PhD}$ candidate \\ Keio University, School of Science and Technology \\ Main research area \\ Urbanism \\ Address \\ 3-14-1 Hiyoshi, Kohoku-ku, Yokohama, Kanagawa 223-8522 Japan \\ Tel. +81-45-566-1675 \\ E-mail: capitanio@keio.jp}

